\title{
Redução da mortalidade neonatal: um desafio atual na agenda de saúde global e nacional
}

\author{
Reduction of neonatal mortality: a current challenge in global and national health agenda
}

Ruth Guinsburg

Em 2003, um sombrio painel em termos de mortalidade infantil foi desenhado por especialistas na área: mais de 10 milhões de crianças menores de cinco anos estavam morrendo a cada ano, quase todas elas em países pobres ou em áreas pobres de países mais desenvolvidos, sendo que $90 \%$ destas mortes ocorriam em 42 países por um pequeno rol de causas que incluía: diarréia, pneumonia, sarampo, malária, HIV/AIDS e mortes neonatais ${ }^{1}$.

Nos dois anos seguintes a estes estudos, estratégias para prevenir a morte de crianças foram implementadas em nível global, nacional e de pesquisa, mas um importante lapso de informações e de ações permanece no que se refere às primeiras quatro semanas de vida, ou seja, o período neonatal. Estima-se que quatro milhões de recém-nascidos faleçam a cada ano no mundo, perfazendo 36\% dos óbitos de crianças com menos de cinco anos ${ }^{2}$. De modo global, as principais causas destes óbitos no período neonatal são: parto prematuro (28\%), infecções graves $(26 \%)$ e asfixia perinatal (23\%). O baixo peso é uma causa indireta importante de morte de recém-nascidos. De acordo com tais observações, 250 recém-nascidos morrem a cada hora no mundo, em sua maioria devido a causas passíveis de prevenção ${ }^{2}$.

No Brasil, a mortalidade neonatal tornou-se o componente mais importante da mortalidade infantil a partir de 1993, passando a representar, em 2001, 65\% dos óbitos de crianças com menos de um ano ${ }^{3-6}$. De acordo com o Ministério da Saúde, em 2001, o número de nascidos vivos no território nacional foi de 3.106.525 e 61.807 destes morreram antes de completar um ano de vida. Os números de óbitos até sete dias de vida e de sete a 28 dias foram, respectivamente, 31.566 e 8.639 em 2001, correspondendo a coeficientes de mortalidade neonatal precoce de 14,0 por mil nascidos vivos e mortalidade neonatal tardia de 3,8 por mil ${ }^{3-6}$.

As intervenções potenciais para reduzir este número elevado de óbitos incluem a melhoria de indicadores como: planejamento familiar, gravidez na adolescência, qualidade da assistência pré-natal, nutrição materna, acompanhamento do trabalho de parto e parto, assistência ao recémnascido na sala de parto e na unidade neonatal e redução do baixo peso ao nascer ${ }^{7}$. Neste sentido, é interessante notar que tais intervenções vêm sendo implementadas em escala reduzida em nosso meio, havendo necessidade de maior vontade política, priorização de necessidades de saúde, organização dos cuidados antenatais e perinatais e educação dos profissionais de saúde, entre outros.

Exemplifica esta afirmação trabalho recente de Barros et $a .^{8}$, que, ao estudar três coortes de nascidos vivos em 1982, 1993 e 2004, mostra um aumento da prevalência de partos prematuros de $6,3 \%$ em 1982 para 16,2\% em 2004, com uma redução média de 47 gramas no peso médio de nascimento. Observa-se, neste estudo, que, embora o número médio de visitas de pré-natal fosse de 8,3 em 2004, a qualidade deste atendimento ainda era em grande parte inadequada: apenas $77 \%$ das gestantes submetidas a exame vaginal, 32\% das gestantes não imunizadas não receberam toxóide tetânico e as taxas de parto cesária subiram de 28\% em 1982 para 43\% em 2004, sendo esta taxa de $82 \%$ quando se consideraram apenas os nascidos em instituições privadas. Ainda neste estudo, as taxas de mortalidade por idade gestacional permaneceram estáveis desde 1993, apesar do aumento da prematuridade, indicando a melhora de qualidade do cuidado pós-natal. Em outro trabalho do mesmo grupo de autores, os dados indicam que a distribuição desigual da tecnologia médica alterou os conceitos relacionados ao parto bom e de qualidade, correlacionando-se com os elevados índices de parto cesária encontrados em nosso país ${ }^{9}$. Chama ainda atenção que, ao analisar etnia e mortalidade neonatal no Brasil, todos os problemas acima assinalados se acentuam: as crianças negras mostram prevalências mais elevadas de baixo peso, prematuridade e de peso pequeno para a idade gestacional, com maior mortalidade nas primeiras quatro semanas de vida. A qualidade do cuidado antenatal é a variável que mais se associa aos achados acima delineados ${ }^{10}$.

Professora Associada e Livre Docente da Disciplina de Pediatria Neonatal da Universidade Federal de São Paulo - Escola Paulista de Medicina UNIFESP - São Paulo (SP) - Brasil.

Correspondência

Rua Vicente Félix 77/09, 01410-020, São Paulo, SP - Telefax: (011)5579-4982 - E-mail: ruthgbr@netpoint.com.br 
É neste contexto que o trabalho apresentado por Giglio et al. ${ }^{11}$, nesta Revista merece uma leitura atenta por todos aqueles interessados na saúde perinatal e nas estratégias necessárias para melhorar os índices elevados de mortalidade neonatal, especialmente a mortalidade neonatal precoce, em nosso meio. Os autores desta pesquisa, com metodologia rigorosa, observam alta taxa de mortalidade neonatal por faixa de peso no município de Goiânia, quando comparada à de países desenvolvidos, sendo fatores de risco para o óbito neonatal a prematuridade, a presença de malformações congênitas, mães em extremos reprodutivos, residência em região de menor nivel sócio-econômico, baixo número de consultas no pré-natal, parto em hospital público e sexo feminino. Excetuandose o sexo (os estudos apontam de maneira quase unânime o maior risco de óbito para os recémnascidos do sexo masculino) e as malformações congênitas (embora os defeitos de tubo neural possam ser reduzidos com a adoção de politica de suplementação universal de alimentos com ácido fólico), todos os outros fatores estudados estão intimamente ligados ao que já foi exposto acima. Ou seja, a mortalidade neonatal associa-se de maneira estreita ao nível sócio-econômico e educacional da população e à qualidade da atenção em saúde oferecida à mulher, em especial à gestante.

Vale frisar que o acesso à educação de bom nível e modo eqüitativo em todo o país deveria contribuir, em longo prazo, para a melhor distribuição de renda e redução dos bolsões de pobreza e miséria, nos quais a mortalidade neonatal atinge seus números mais elevados. A educação em saúde e em métodos anticoncepcionais poderia reduzir a incidência de gravidez nos extremos reprodutivos da vida fértil da mulher, em especial na adolescência. A melhora da assistência antenatal poderia proporcionar redução da mortalidade perinatal ao detectar e tratar doenças maternas, ao melhorar a nutrição materna, ao efetivar a vacinação contra o tétano, ao prover informação relativa aos malefícios de fumar e beber durante a gravidez e ao orientar e educar a respeito dos benefícios do parto normal (ou dos problemas relacionados à indicação de cesárea eletiva sem trabalho de parto, "com hora marcada") e do aleitamento materno. Estas práticas poderiam diminuir as mortes de recém-nascidos causadas por parto prematuro, baixo peso ao nascer e sindrome do desconforto respiratório, entre outras ${ }^{7}$.

É neste contexto que vale reiterar a afirmativa de De Carvalho e Gomes ${ }^{6}$, em publicação recente no Jornal de Pediatria “... inúmeras dificuldades no lugar de garantia de acesso, a iniqüidade onde deveriamos encontrar eqüidade, a desorganização e fragmentação ao invés da regionalização e hierarquização do sistema, bem como as preocupantes e freqüentes inadequações técnico-científicas na assistência, ainda se apresentam como desafios muito vivos para a gestão pública do atendimento perinatal em nosso país”.

\section{Referências}

1. Jones G, Steketee RW, Black RE, Bhutta ZA, Morris SS; Bellagio Child Survival Study Group. How many child deaths can we prevent this year? Lancet. 2003;362(9377):65-71.

2. Lawn JE, Cousens S, Zupan J; Lancet Neonatal Survival Steering Team. 4 million neonatal deaths: when? Where? Why? Lancet. 2005;365(9462):891-900.

3. Ministério da Saúde. Fundação Nacional de Saúde. Nascidos vivos - Brasil. 2000-2002 [homepage na Internet]. Brasília; 2004 [citado 2004 Dez 15]. Disponivel em: http//datasus.gov.br

4. Ministério da Saúde. Fundação Nacional de Saúde. Indicadores demográficos - Brasil. 2000 e 2001 [homepage na Internet]. Brasília; 2004 [citado 2004 Dez 15]. Disponível em: http//datasus.gov.br

5. Ministério da Saúde. Fundação Nacional de Saúde. Mortalidade infantil. 2001 [homepage na Internet]. Brasília; 2004 [citado 2004 Dez 15]. Disponivel em: http//www.funasa.gov.br

6. De Carvalho M, Gomes MA. A mortalidade do prematuro extremo em nosso meio: realidade e desafios. J Pediatr (Rio J). 2005;81(1 Suppl):S111-8.

7. Victora CG, Barros FC. Infant mortality due to perinatal causes in Brazil: trends, regional patterns and possible interventions. Sao Paulo Med J. 2001;119(1):33-42.

8. Barros FC, Victora CG, Barros AJ, Santos IS, Albernaz E, Matijasevich A, et al. The challenge of reducing neonatal mortality in middle-income countries: findings from three Brazilian birth cohorts in 1982, 1993, and 2004. Lancet. 2005;365(9462):847-54.

9. Behague DP, Victora CG, Barros FC. Consumer demand for caesarean sections in Brazil: informed decision making, patient choice, or social inequality? A population based birth cohort study linking ethnographic and epidemiological methods. BMJ. 2002;324(7343):942-5.

10. Barros FC, Victora CG, Horta BL. Ethnicity and infant health in southern Brazil. A birth cohort study. Int J Epidemiol. 2001;30(5):1001-8.

11. Giglio MRP, Lamounier JA, Morais Neto OL, César CC. Baixo peso ao nascer em coorte de recém-nascidos em Goiânia-Brasil no ano de 2000. Rev Bras Ginecol Obstet. 2005; 27(3):130-6. 